\title{
Marie-Laure Basuyaux, Témoigner clandestinement. Les récits lazaréens de Jean Cayrol
}

\section{Margareth Amatulli}

\section{(2) OpenEdition}

1 Journals

\section{Edizione digitale}

URL: http://journals.openedition.org/studifrancesi/7714

DOI: $10.4000 /$ studifrancesi. 7714

ISSN: 2421-5856

\section{Editore}

Rosenberg \& Sellier

\section{Edizione cartacea}

Data di pubblicazione: 1 décembre 2009

Paginazione: 668

ISSN: 0039-2944

\section{Notizia bibliografica digitale}

Margareth Amatulli, «Marie-Laure Basuyaux, Témoigner clandestinement. Les récits lazaréens de Jean Cayrol», Studi Francesi [Online], 159 (LIII | III) | 2009, online dal 30 novembre 2015, consultato il 09 janvier 2021. URL: http://journals.openedition.org/studifrancesi/7714 ; DOI: https://doi.org/10.4000/ studifrancesi.7714

Questo documento è stato generato automaticamente il 9 janvier 2021.

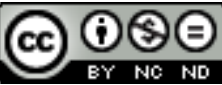

Studi Francesi è distribuita con Licenza Creative Commons Attribuzione - Non commerciale - Non opere derivate 4.0 Internazionale. 


\title{
Marie-Laure Basuyaux, Témoigner clandestinement. Les récits lazaréens de Jean Cayrol
}

\author{
Margareth Amatulli
}

\section{NOTIZIA}

MARIE-LAURE BASUYAUX, Témoigner clandestinement. Les récits lazaréens de Jean Cayrol, Paris, Éditions Classiques Garnier, 2009, pp. 633.

1 A distanza di quattro anni dalla morte di Jean Cayrol, il voluminoso saggio di MarieLaure Basuyaux colma una profonda lacuna nella letteratura critica sull'opera di questo scrittore che, nonostante Roland Barthes lo riconoscesse come uno dei padri del Nouveau Roman, non ha goduto dell'attenzione dovuta. La monografia, che si apre proprio sui problemi di ricezione, si concentra sull'analisi di dodici romanzi (On vous parle e Les Premiers Jours del 1947; La Noire, 1949; Le Feu qui prend, 1950; Le Vent de la mémoire, 1952; L'Espace d'une nuit, 1954; Le Déménagement, 1956; La Gaffe, 1957; Les Corps étrangers, 1959; Le Froid du soleil, 1963; Midi-Minuit, 1966; Je l'entends encore, 1968) pubblicati da Cayrol in quella che M.-L. Basuyaux considera per motivi storici, biografici e interni all'opera la prima fase della sua produzione, ossia gli anni che vanno dal ritorno dai campi di concentramento sino al 1968. Dal confronto di questi romanzi con le riflessioni teoriche dello scrittore e, in particolare, con i testi che appartengono alla letteratura dei campi emerge la genesi e l'evoluzione di una specifica poetica postconcentrazionaria, e la singolarità di una finzione che senza raccontare direttamente la deportazione ne porta traccia nella sua stessa forma. Nella prima delle quattro parti in cui si articola il volume (Le «romanesque lazaréen») l'esperienza vissuta da Jean Cayrol viene inclusa in uno spazio letterario che vede protagonista, tra le altre, la lettura di Kafka e dei racconti sui campi di concentramento già pubblicati nell'immediato dopoguerra, con i quali le opere dell'autore condividono un ampio sistema di equivalenze sul piano dei motivi (come il fascino per il famelico, i personaggi senza 
qualità), delle strutture della narrazione (la comune scansione viaggio-morte-ritorno) e della dinamica della scrittura che spesso si articola proprio a partire da una risemantizzazione di termini provenienti dall'ambito della deportazione o che proprio in alcuni di essi trova la sua matrice metaforica. Tale analogie concentrationnaire (dal titolo della seconda parte) si condensa nel motivo della parola, analizzato nella terza parte, intitolata Poétique de l'énonciation: accurata disamina di quei procedimenti stilistici attraverso cui la retorica dell'indicibile teorizzata nei racconti concentrazionari si incarna materialmente nelle finzioni di Cayrol, abitate da personaggi prolissi, da voci precarie a contatto con una realtà sfuggente, da una parola destinata al soliloquio e da una sintassi concitata. Nell'ultima parte (Une fiction sans catharsis) vengono analizzati quei dispositivi che, contravvenendo alla logica tipica della finzione, negano qualunque effetto catartico. Combattuta tra «le refus des séductions et de l'appropriation propres à la lecture d'un texte de fiction»e «le refus de la mise à distance radicale» (p. 542), l'opera di Cayrol, alla continua ricerca delle sue forme, si costruisce su un simile spazio di tensione tra letteratura di testimonianza e Nouveau Roman e, più generalmente, «entre une littérature de l'expérience et une littérature expérimentale» (p. 548).

2 La ricca e approfondita bibliografia che chiude il volume consegna per la prima volta al lettore un repertorio esaustivo dell'opera di Cayrol e della letteratura critica a lui consacrata, e offre allo studioso un prezioso stimolo per ulteriori analisi. 